University of Rhode Island

DigitalCommons@URI

Ocean Engineering Faculty Publications

Ocean Engineering

1991

\title{
Marine sediment classification using the chirp sonar
}

Lester R. LeBlanc

Larry Mayer

Manuel Rufino

University of Rhode Island

Steven G. Schock

John King

University of Rhode Island, jwking@uri.edu

Follow this and additional works at: https://digitalcommons.uri.edu/oce_facpubs

Terms of Use

All rights reserved under copyright.

\section{Citation/Publisher Attribution}

LeBlanc, L. R., Mayer, L., Rufino, M., Schock, S. G., \& King, J. (1991). Marine sediment classification using the chirp sonar. The Journal of the Acoustical Society of America, 91(1), 107-115. doi: 10.1121/1.402758 Available at: http://dx.doi.org/10.1121/1.402758

This Article is brought to you for free and open access by the Ocean Engineering at DigitalCommons@URI. It has been accepted for inclusion in Ocean Engineering Faculty Publications by an authorized administrator of DigitalCommons@URI.For more information, please contact digitalcommons-group@uri.edu. 


\section{Marine sediment classification using the chirp sonar}

Lester R. LeBlanc, Larry Mayer, Manuel Rufino, Steven G. Schock, and John King

Citation: The Journal of the Acoustical Society of America 91, 107 (1992); doi: 10.1121/1.402758

View online: https://doi.org/10.1121/1.402758

View Table of Contents: http://asa.scitation.org/toc/jas/91/1

Published by the Acoustical Society of America

\section{Articles you may be interested in}

Sonar attenuation modeling for classification of marine sediments

The Journal of the Acoustical Society of America 91, 116 (1992); 10.1121/1.402759

Sediment classification based on impedance and attenuation estimation

The Journal of the Acoustical Society of America 96, 3022 (1994); 10.1121/1.411266

High-resolution sonar volume scattering measurements in marine sediments

The Journal of the Acoustical Society of America 97, 2979 (1995); 10.1121/1.411861

Model-based sediment classification using single-beam echosounder signals

The Journal of the Acoustical Society of America 129, 2878 (2011); 10.1121/1.3569718

Geoacoustic modeling of the sea floor

The Journal of the Acoustical Society of America 68, 1313 (1980); 10.1121/1.385100

Riverbed sediment classification using multi-beam echo-sounder backscatter data

The Journal of the Acoustical Society of America 126, 1724 (2009); 10.1121/1.3205397 


\section{Marine sediment classification using the chirp sonar}

Lester R. LeBlanc

Department of Ocean Engineering, Florida Atlantic University, Boca Raton, Florida 33431-0991

Larry Mayer

Dalhousie University, Halifax, Nova Scotia B3H 4J1, Canada

Manuel Rufino

Department of Ocean Engineering, University of Rhode Island, Narragansett, Rhode Island 02882

Steven G. Schock

Department of Ocean Engineering, Florida Atlantic University, Boca Raton, Florida 33431-0991

John King

Graduate School of Oceanography, University of Rhode Island, Narragansett, Rhode Island 02882

(Received 1 March 1991; accepted for publication 12 September 1991)

The chirp sonar is a calibrated wideband digital FM sonar that provides quantitative, highresolution, low-noise subbottom data. In addition, it generates an acoustic pulse with special frequency domain weighting that provides nearly constant resolution with depth. The chirp sonar was developed with the objective of remote acoustic classification of seafloor sediments. In addition to producing high-resolution images, the calibrated digitally recorded data are processed to estimate surficial reflection coefficients as well as a complete sediment acoustic impulse profile. In this paper, surficial sediments in Narragansett Bay, RI are used to provide ground truth for an acoustic model. Quantitative acoustic returns from the chirp sonar are used to estimate surficial acoustic impedance and to predict sediment properties. A robust acoustic sediment classification model that uses core samples to account for the local depositional environment has been developed. The model uses an estimate of acoustic impedance to predict surficial density, porosity, compressibility, and rigidity. The comparisons show a high correlation between the core-determined sediment properties and the estimates obtained from acoustic measurements.

PACS numbers: 43.30.Ma, 43.30.Vh

\section{INTRODUCTION}

The remote classification of marine sediments by acoustic means requires a quantitative, high-resolution profiling system as well as a solid theoretical and/or empirically derived basis upon which to convert the acoustic measurements into the desired sediment properties. Recent advances in subbottom profiler design have produced high-quality data suitable for sediment classification work. ${ }^{1}$ The collection and acoustic analysis of cores taken in conjunction with these seismic surveys provides a database for developing algorithms for sediment property prediction as well as "ground truthing" of the profiler's ability to remotely identify sediment type.

In this paper we describe an experiment conducted in Narragansett Bay, RI, using the chirp sonar, a calibrated, wideband $(2-10 \mathrm{kHz})$, digital FM sonar that provides quantitative, high-resolution $(\approx 10 \mathrm{~cm})$, deep penetration $\left(\approx 100 \mathrm{~m}\right.$ ) subbottom data. ${ }^{1,2}$ The chirp sonar was developed with ONR funding to support the objective of remote acoustic classification of marine sediments. In addition to producing high-resolution images of the subsurface, the calibrated digitally recorded data can be processed to provide surficial reflectivity estimates. Subbottom returns can also be processed for attenuation ${ }^{1}$ and when corrected for attenuation, chirp sonar profiles can provide a reflectivity series well suited for acoustic impedance inversion.

Along with chirp sonar profiles, cores were collected in Narragansett Bay. These cores were analyzed for velocity, density, porosity, grain density, and grain size. There is a wealth of literature describing empirical studies of sediment physical and acoustic property relationships. ${ }^{3-8}$ These studies have resulted in a number of regression equations that can often be successful in their ability to predict one property from another (typically within a given depositional environment) but have provided only limited insight into the interaction between acoustic waves and marine sediments. Theoretical studies of sediment-acoustic wave interaction, on the other hand, particularly those of Biot ${ }^{9,10}$ and Stoll ${ }^{11}$ have used sophisticated formulations that take into account the sediment frame properties. In this paper we have initially taken a simplified view of the manner in which a normally incident acoustic wave emitted from an acoustic profiler interacts with a fully saturated marine sediment. In our model, we have assumed that the marine sediment is macroscopically homogeneous and that most of the acoustic-marine sediment interaction can be accounted for by the bulk properties of the sediment, i.e., porosity, specific gravity, elasticity, and 
rigidity. The problem of extracting quantitative sediment parameters from normal incidence reflection profiles poses a difficult challenge. Even under the most ideal conditions, the acoustic wave energy is scattered by the random unevenness of the seafloor and the inhomogeneities within the sediment. In order to extract any meaningful information from the stochastic acoustic signal that is returned from the seabed, a model with significant averaging of the estimated parameters is required. The model developed in this paper has enough flexibility to model most surficial sediment depositional environments. Further, the model can be calibrated to a local area by using average grain density, grain elasticity, and a rigidity constant obtained from core samples. In this manner, chirp profiler data obtained using a 2-to $10-\mathrm{kHz}$ swept FM is processed to provide reasonable predictions of sediment type.

\section{CHIRP SONAR DESCRIPTION}

The chirp sonar system shown in Fig. 1 uses a linearly swept FM pulse that typically covers the range of frequencies from $2-10 \mathrm{kHz}$. The rectangular acoustic projector is constructed from four wideband piston type transducers and the acoustic receiver is a ceramic line array. The acoustic arrays are mounted in a tow vehicle that is designed for profiling at ship speeds varying from 0 (drifting) to $10 \mathrm{kn}$. Separate receiving and transmitting arrays are used to preserve linearity and to allow simultaneous transmission and reception. The receiver array signal is digitized with a 16-bit A/D converter at a sampling rate of $30 \mathrm{kHz}$. To achieve the theoretical temporal resolution predicted by the inverse of the bandwidth, the chirp pulse is compressed using a matched filter that correlates the chirp return signal with a replica of the outgoing pulse. The correlation process is implemented with a discrete Fourier transform which is calculated in real time with a pipeline array processor. The hardware used to accomplish this is a AT\&T DSP 32c processor controlled by

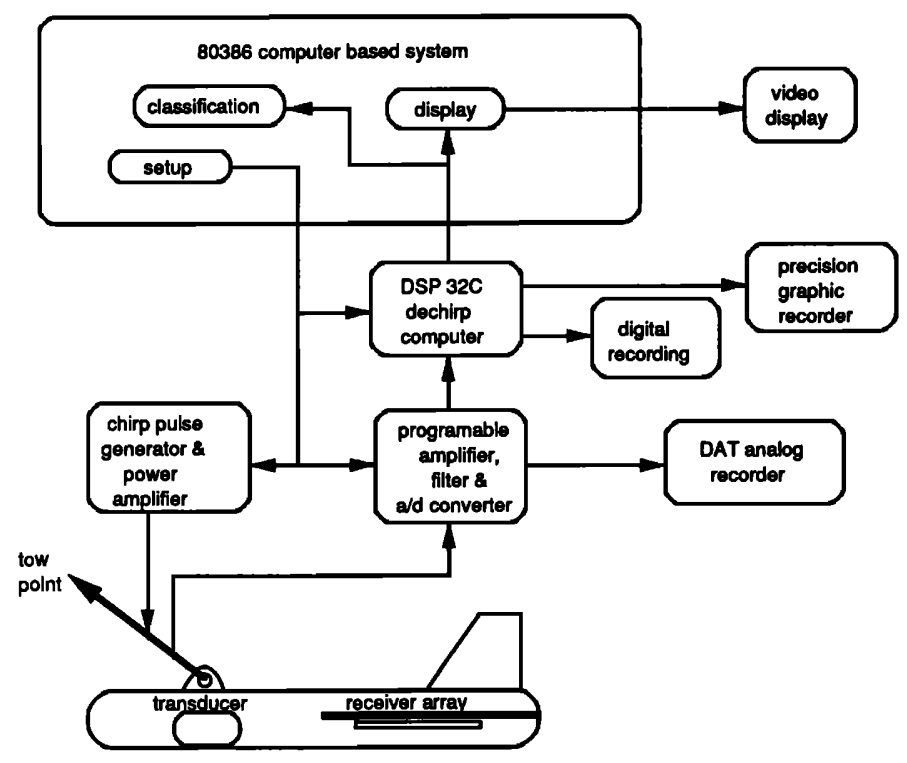

FIG. 1. Chirp sonar system components. a 80386 microcomputer. The compressed pulse resulting from this signal processing procedure has a time duration approximately equal to the inverse of the bandwidth of the chirp pulse. Good resolution is an important factor in sediment classification because it provides a more precise picture of the true geologic variability (the impulse response of the sediment), and thus permits accurate determination of the depositional processes. When the time duration of the processed pulse is too large, individual reflections will be lumped together with random phase, thus making it difficult to estimate impedance and to examine geologic processes.

In addition to the pulse compression correlation processing achieves a signal processing gain over the background noise. This gain is approximately ten times the log of the time-bandwidth product. To equal the performance of the chirp sonar pulses that were used in this experiment, a conventional pulse sonar would have to operate at a peak pulse power of 100 times larger than the chirp pulse.

Another important feature that enhances the ability of the chirp sonar system to classify sediments is realized by the deconvolution of the system response from the output pulse. The sonar system impulse response is measured in the laboratory and is used to design a unique output pulse that will prevent the source from ringing. In addition to this, the chirp wavelet is weighted in the frequency domain so as to have a Gaussian-like shape. As the Gaussian-shaped spectrum is attenuated by the sediment, energy is lost but its bandwidth is nearly preserved. ${ }^{12}$ Thus even after being attenuated by 20 $\mathrm{m}$ of sand, the chirp pulse has approximately the same resolution as an unattenuated pulse. This feature simplifies the mathematics of inverting the time series to obtain the impedance profile of the sediment. In addition to a loss of total energy, attenuation causes the center frequency of the chirp pulse spectrum to shift to a lower frequency, thus allowing us to estimate the attenuation of the sediment.

Another important feature of the chirp sonar is the reduction of side lobes in the effective transducer aperture. The wide bandwidth of the FM sweep has the effect of smearing the side lobes of the transducer and thus achieving a beam pattern with virtually no side lobes. The effective spatial beamwidth obtained after processing the chirp signal is $20^{\circ}$ measured to the $-3-\mathrm{dB}$ points. This feature is apparent when inspecting the sample profile record shown in Fig. 2.

Since the transmitted chirp pulse is highly repeatable and its peak amplitude is precisely known, the sediment reflectivity values can be estimated from the peak pulse amplitude measurements of the bottom returns. In this experiment, peak pulse amplitude was recorded while surveying a section of Narragansett Bay. When an interesting feature appeared, grab samples were taken at that station. The samples were analyzed for grain size, porosity, and sound speed, and then compared to the chirp sonar estimated sediment impedance.

\section{BOTTOM LOSS MEASUREMENT AND SEAFLOOR CLASSIFICATION}

When an acoustic wave traveling through the water encounters the sediment boundary of the seafloor, reflected 


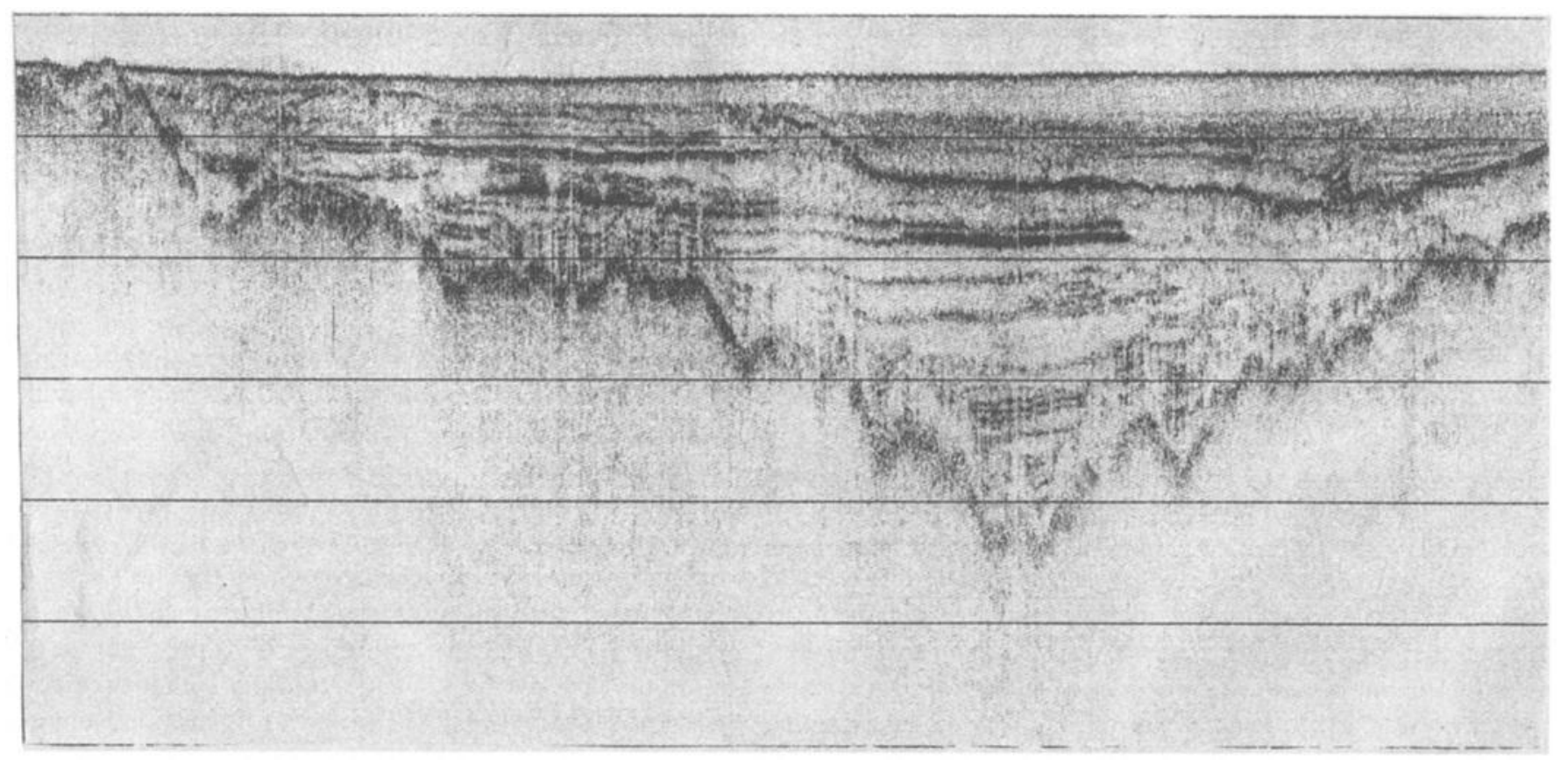

FIG. 2. Typical chirp profile in Narragansett Bay, RI taken between the Wickford breakwall and Hope Island; horizontal extent is about $1500 \mathrm{~m}$ and vertical scale is $10 \mathrm{~m}$ between grid lines. The record reveals: a glacially excavated river valley overlain by approximately $30 \mathrm{~m}$ of varved glacial lake deposits; a fluvial uncomformity at the top of the lake sediments and; approximately $10 \mathrm{~m}$ of marine estuarine sediments deposited with the most recent rise of sea level.

and transmitted waves are generated at the fluid-sediment boundary. For a simple harmonic plane wave normally incident on a plane boundary, the Rayleigh reflection coefficient is given by,

$$
R=\left(\rho_{b} c_{b}-\rho_{w} c_{w}\right) /\left(\rho_{b} c_{b}+\rho_{w} c_{w}\right)
$$

and the bottom loss $(\mathrm{BL})$ of the plane wave at normal incidence is then given by

$$
\mathrm{BL}=-20 \log _{10}(R) .
$$

Initially, we are using this equation as the basis for classifying surficial sediments on the seafloor.

Obviously, there are many approximations that can modify our analysis; seafloor roughness, planar wave assumption, other waves generated at the boundary, ${ }^{13}$ and bottom curvature to mention a few. To some extent, the effects of seafloor roughness can be reduced by averaging the reflected values. In addition to the mean value, the reflected pulse width and pulse amplitude variance are indicators of sediment types. In this experiment, we used the mean amplitude to determine bottom type. In several instances, gaseous sediments were brought up in the grab corer and in each case, a broadening of the reflected pulse was noticed. In shallow coastal areas, gaseous surficial sediments are quite often present. These sediments present a large reflection coefficient while providing volume scattering that lengthens the pulse returned from the boundary. ${ }^{14}$ In the future, our program will include these effects as well as accomplish a mathematical impedance inversion to obtain the acoustic impulse response of the sonified column of marine sediment.

\section{RELATIONSHIP BETWEEN SEDIMENT PROPERTIES AND BOTTOM LOSS}

An unconsolidated marine sediment is a porous and loose structure whose interstices are filled with seawater. Therefore, it can be thought of as composed of a fraction which is seawater and a remainder which is solid material. Porosity, which is defined as the ratio of the volume of voids between the grains of a sediment to the total volume of the sediment aggregate is therefore an important parameter in describing the way marine sediments react acoustically.

The relationship between bulk density of a marine sediment and porosity is given by

$$
\rho_{b}=\rho_{w} n+\rho_{g}(1-n),
$$

where $\rho_{b}$ is the bulk density of the sediment, $\rho_{w}$ is the density of bottom water, $\rho_{g}$ is the density of the solid material (grain density), and $n$ is the porosity of the sediment. This is a simple linear relationship that is easily derived by considering the total mass of material enclosed in a unit volume made up of two materials. In Eq. (3), the porosity $n$ is easily obtained as a function of density:

$$
n=\left(\rho_{g}-\rho_{w}\right) /\left(\rho_{g}-\rho_{b}\right) .
$$

The compressional wave velocity for a wave in isotropic elastic media ${ }^{15}$ is well known and is given by

$$
c_{b}=\left(\frac{1 / \beta_{b}+4 \mu / 3}{\rho_{b}}\right)^{1 / 2},
$$

where $\beta_{b}$ is the bulk compressibility of the water saturated 
sediment, and $\mu$ is the bulk modulus of rigidity. For small pressure perturbations, the bulk compressibility is linearly dependent on the porosity of the sediment.

For an adiabatic process, the compressibility is defined as the fractional change in a unit volume of material for a given change in pressure:

$$
\beta_{b}=\frac{1}{V} \frac{\partial V}{\partial p} \text {. }
$$

Thus the fractional change in a unit volume of water saturated sediment is a linear combination of the individual compressibility of each material, and is given by

$$
\begin{aligned}
\beta_{b}=\frac{1}{V} \frac{\partial V}{\partial p} & =\frac{V_{w}}{V}\left(\frac{1}{V_{w}} \frac{\partial V_{w}}{\partial p}\right)+\frac{V_{g}}{V}\left(\frac{1}{V_{g}} \frac{\partial V_{g}}{\partial p}\right) \\
& =\beta_{w} n+\beta_{g}(1-n),
\end{aligned}
$$

where $\beta_{w}$ is the compressibility of water and $\beta_{g}$ is the compressibility of the solid material (grain compressibility). The characteristic acoustic impedance $\left(\rho_{b} c_{b}\right)$ of the marine sediment is now obtained by combining Eqs. (3), (5), and (7) as follows,

$$
\begin{aligned}
Z_{b} & =\rho_{b} c_{b} \\
& =Z_{w}\left(\frac{n+\rho_{R}(1-n)}{n+\beta_{R}(1-n)}+\frac{4}{3} \mu \beta_{w}\left[n+\rho_{R}(1-n)\right]\right)^{1 / 2},
\end{aligned}
$$

where $\rho_{R}=\rho_{g} / \rho_{w}$ is the grain density relative to bottom water, $\approx 2-3 ; \rho_{w}$ is the density of bottom water, $1025 \mathrm{~kg} / \mathrm{m}^{3}$; $\beta_{R}=\beta_{g} / \beta_{w}$ is the grain compressibility relative to bottom water, $\approx 0-1 ; \beta_{w}$ is the compressibility of bottom water, $42.94 \times 10^{-11} \mathrm{~m}^{2} / \mathrm{N}$ (Ref.7); and $Z_{w}=\left(\rho_{w} / \beta_{w}\right)^{1 / 2}$ is the impedance of bottom water, $1.549 \times 10^{6} \mathrm{~kg} / \mathrm{m}^{2} \mathrm{~s}$ (note$\rho_{w}, \rho_{g}, \beta_{w}, \beta_{g}$, referred to 1 atm and $23^{\circ} \mathrm{C}$ ).

The compressional wave velocity of the sediment is obtained in the same manner by combining Eqs. (3) and (7) with (5):

$$
\begin{aligned}
c_{b}= & c_{w}\left(\frac{1}{\left[n+\beta_{R}(1-n)\right]\left[n+\rho_{R}(1-n)\right]}\right. \\
& \left.+\frac{4 / 3 \mu \beta_{w}}{\left[n+\rho_{R}(1-n)\right]}\right)^{1 / 2},
\end{aligned}
$$

where $c_{w}=\sqrt{1 / \beta_{w} \rho_{w}}$ is the compressional wave velocity of bottom water, $1.504 \times 10^{3} \mathrm{~m} / \mathrm{s}$.

Equations (8) and (9) relate the porosity and rigidity properties of a given marine sediment sample to acoustic impedance and sound velocity. In a given depositional environment, it is hypothesized that the relative grain density $\rho_{R}$ and the relative grain compressibility $\beta_{R}$ in Eqs. (8) and (9) are nearly constant and therefore porosity and rigidity are the governing factors in determining the acoustic impedance of the surficial sediments.

In order to test this hypothesis, independent sets of impedance versus density, and impedance versus porosity data were collected from five references. ${ }^{3-7}$ All of the samples were near-surface samples taken in coastal regions (terrigenous sediments). The data from these references were used in a nonlinear least-squares curve fitting process so as to obtain the average $\rho_{R}, \beta_{R}$, and $\mu$ corresponding to the coastal depositional environment that the samples were taken from. The curve fitting process is carried out in two stages: The first stage is initiated by starting with an initial estimate of relative density, relative compressibility, and rigidity. The first two of these starting values are varied until a minimum leastsquares fit is obtained between the measured impedance values and the impedance values predicted by Eq. (8). In the second stage, the second group of measurements (impedance density) are used to find the rigidity constant that again produces a least-squares fit of Eq. (8) to the actual impedance measurements. In order to accomplish this, the density values were first converted to porosity by using Eq. (4) and then porosity data was used directly in Eq. (8) to calculate impedance. The process of adjusting the $\rho_{R}$ and $\beta_{R}$ in the first least-squares solution and then rigidity $\mu$ in the second solution, is repeated in this same manner until the errors in both curves are globally minimized. This procedure is used to obtain a set of constants $\rho_{R}, \beta_{R}$, and $\mu$ that provides us with a calibration of Eq. (8) to a given depositional environment.

Before carrying out the above-mentioned procedure to solve for the sediment parameters, another minor refinement was required to the rigidity term in Eq. (8). Based on a careful observation of the data collected for this study, it is suggested that rigidity of surficial sediments is dependent on the percentage of solid content in a marine sediment. This concept was empirically tested by assuming the following equation for the dependence of rigidity on density,

$$
\mu=\mu_{0}\left(\rho_{b} / \rho_{w}-1\right)^{\eta},
$$

where $\mu_{0}$ is the rigidity constant-a function of depositional environment, $\left(\rho_{b} / \rho_{w}-1\right)$ is a quantity that is proportional to the solid material in a unit volume of marine sediment, and $\eta$ is an arbitrary exponential power constant $(\eta \approx 1)$.

Figure 3 is a plot showing the impedance versus porosity and impedance versus (density -1 ); both "actual data" and the least-squares fit of Eq. (8) to the data are plotted. The rms error in the curve fit is about $4 \%$ indicating a high correlation between the group of data taken from Refs. 3-7 and the theory developed herein. Prior to including the rigid-

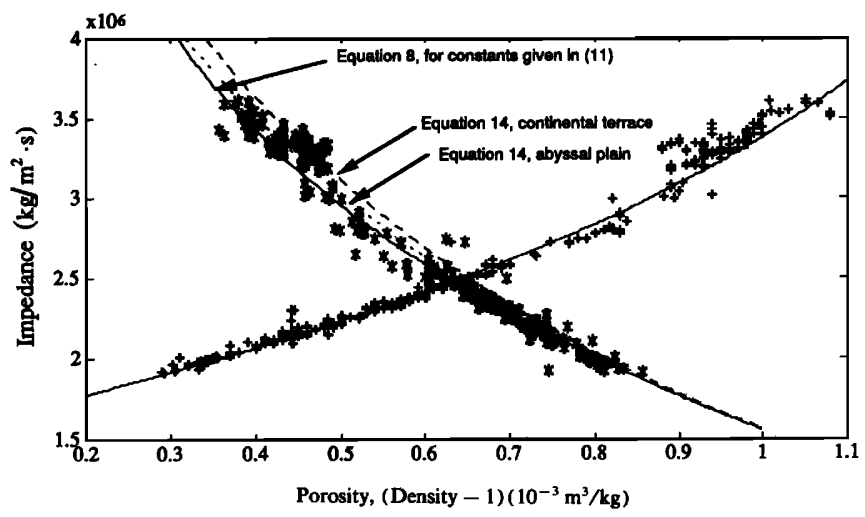

FIG. 3. Impedance as a function of both porosity (*) and (density - 1) $(+)$ for actual data taken from five references and the least-squares curve fitting of Eq. (8) to the data. Other curves are from Ref. 6. 
ity term in Eqs. (8) and (9), the rms error was about $5 \%$ greater.

In carrying out the least-squares fit, the power $\eta$ in Eq. (10) was allowed to vary so as to determine its relationship to various depositional environments. In all cases, it was found that $\eta$ was very close to 1 , and based on this result, $\eta$ was fixed at a value of one and $\mu_{0}$ was recalculated for all of the data sets. It is not too unreasonable to expect the rigidity of a sediment to vary in a linear manner $(\eta=1)$ with the composition of solid material in the marine sediment. The remainder of the constants obtained by the least-squares fitting procedure are in the proper range for terrigenous sediments and are given here:

grain density

$$
\rho_{g}=\rho_{w} \rho_{R}=2670 \mathrm{~kg} / \mathrm{m}^{3},
$$$$
\text { grain compressibility } \beta_{g}=\beta_{w} \beta_{R}=4.85 \times 10^{-11} \mathrm{~m}^{2} / \mathrm{N} \text {, }
$$$$
\text { rigidity constant } \quad \mu_{0}=0.0005 \times 10^{11} \mathrm{~N} / \mathrm{m}^{2} \text {. }
$$

The plane-wave pressure reflection coefficient is easily related to the porosity or density by noting from Eq. (1),

$$
R=\left(Z_{b}-Z_{w}\right) /\left(Z_{b}+Z_{w}\right),
$$

where $Z$ is obtained either by direct substitution of the porosity, $n$ into Eq. (8) or indirectly, by finding the porosity from the density values using Eq. (4), and then substituting into Eq. (8). The solid line in Fig. 4 is a plot of reflection coeffcient as a function of porosity. It is the result of using the previously derived grain characteristics $\left(\rho_{g}, \beta_{g}, \mu_{0}\right)$ in Eq. (8). Faas ${ }^{8}$ used density and compressional sound velocity data from four separate references to compile impedance data. The data were then used in a linear least-squares fit to obtain an empirical equation that relates the reflection coefficient to porosity,

$$
R=0.6468-0.6456 n \quad(0.35 \leqslant n \leqslant 0.85) .
$$

Data taken from this equation are plotted for comparative purposes on the same figure. The empirical equation is only valid in the limited range given above. However, in this range, there is an excellent correspondence between our Eq. (8) derived from basic physical principles, and the empirical relationship given by Eq. (13). Part of the high degree of correspondence is attributed to some overlap in data sets used in both methods. Nevertheless, the comparison is en-

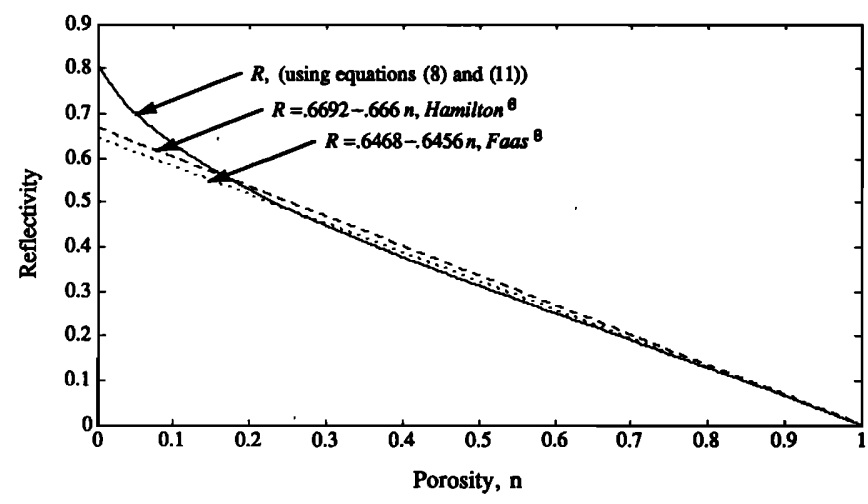

FIG. 4. Hamilton's and Faas's empirical equations for reflection coefficient compared to Eq. (8) derived in text. couraging and points to a more quantitative way of characterizing the depositional environment. To account for different depositional environments, Hamilton proposed three empirical equations for relating porosity to reflection coefficient:

$$
\begin{aligned}
& R=0.6692-0.666 n ; \text { continental terrace, } \\
& R=0.6199-0.607 n ; \text { abyssal hill, } \\
& R=0.6461-0.646 n ; \text { abyssal plain, }
\end{aligned}
$$

where $0.35 \leqslant n \leqslant 0.85$.

For comparison, data from Hamilton's continental terrace equation are also plotted in Fig. 4. All of these empirical equations constitute attempts to relate the functional behavior between reflection coefficient and porosity to a given depositional environment in a qualitative manner. Using the method developed in this paper, we are able to establish a quantitative method of characterizing the depositional environment. This is accomplished by specifying grain density, compressibility, and rigidity values in Eq. (8). In order to obtain these parameters, in a given geographic area, a limited set of cores and knowledge of the geological depositional processes involved could be combined to provide an estimate of the constants. Using this simple calibration procedure, normal incident reflectivity values obtained from the chirp sonar are used to predict porosity, density, grain size, rigidity, and sound velocity.

Hamilton $^{6}$ developed another empirical relationship that can be used to provide an estimate of grain diameter from porosity:

$$
n=31.05+5.52 \Phi \text {, }
$$

where $\Phi=-\log _{2}$ (mean grain diameter in $\mathrm{mm}$ ), and $1 \leqslant \Phi \leqslant 9$.

The correlation between porosity and mean grain diameter is not as well defined as the correlation between porosity and density. The standardized error is of the order of $30 \%$. Theoretically, the actual size of each grain in a sediment has no influence on the porosity if the grains were uniform spheres. In actuality, as the grain size decreases, friction, adhesion, and bridging increases. Thus a correlation exists between mean grain diameter and porosity but the relationship is complex.

For the purpose of providing a general class name to a given sediment in this experiment, Hamilton's table for the continental terrace (Table I) was used to relate measured

TABLE I. Sediment reflection coefficient and bottom loss for continental terrace. $^{6}$

\begin{tabular}{lrl}
\hline \hline Sediment type & \multicolumn{2}{c}{ Average reflection coefficient } \\
\hline Coarse sand & 0.4098 & $(-7.8 \mathrm{~dB})$ \\
Fine sand & 0.3749 & $(-8.5 \mathrm{~dB})$ \\
Very fine sand & 0.3517 & $(-9.1 \mathrm{~dB})$ \\
Silty sand & 0.3228 & $(-9.8 \mathrm{~dB})$ \\
Sandy silt & 0.2136 & $(-13.4 \mathrm{~dB})$ \\
Sand-silt-clay & 0.2504 & $(-12 \mathrm{~dB})$ \\
Clayey silt & 0.1767 & $(-15 \mathrm{~dB})$ \\
Silty clay & 0.1586 & $(-16 \mathrm{~dB})$ \\
\hline \hline
\end{tabular}


reflection coefficient values to sediment type.

This general relationship between class names and sediments is based on a recommendation by Shepard ${ }^{16}$ which accounts for proportions of sand, silt, and clay present. A general relationship like this is possible since sands have less porosity than silts and clays and the latter are more porous.

\section{CLASSIFICATION OF MARINE SEDIMENTS USING THE CHIRP SONAR}

Since the chirp sonar is a digital FM system, the amplitude of the correlated sediment-water interface reflection is accurately measured and recorded. As shown in Fig. 5, the reflection coefficient of the first bottom arrival is detected and corrected for geometric spreading. These raw values are averaged over several returns $(\approx 10-100)$ to reduce the undesirable effects of noise, scattering, and an uneven bottom. The unscaled reflection coefficient values are then converted to $\mathrm{dB}$ values, $R_{\mathrm{db}}=-20 \log (R)$. Using the sonar equation, the system calibration constant is now subtracted from the estimated, unscaled reflection values to obtain the reflection loss of the seafloor. The system calibration constant used in this equation can be obtained by either a direct tank calibration, or by an indirect method using a known seafloor type, or a flat reflecting plate target placed at a fixed distance from the transmitter and receiver pair. The impedance estimate of the seafloor is now obtained from

$$
Z_{b}=Z_{w}[(1+R) /(1-R)] \text {. }
$$

Equations (8) and (9) are now solved to obtain porosity and sound velocity estimates for the marine sediment. Equation (3) is used to find a density estimate, Eq. (10) to find a rigidity estimate and finally, Eq. (15) is used to obtain an estimate of average grain size.

\section{EXPERIMENT AND RESULTS}

A seafloor reflectivity survey was carried out in Narragansett Bay, RI in May 1990 and a second experiment later in Sept. 1990. The chirp sonar (Fig. 1) system was set up and calibrated to transmit a 20-ms pulse ranging in frequency from 2 to $9 \mathrm{kHz}$ at a rate of twice per second. In the first experiment in May, the system was calibrated by using a large area of seafloor of known sediment type (sand, sandy silt, clayey silt) in Narragansett Bay. Other areas in the bay were then analyzed by the chirp system and compared to previous ground truth (cores) data. In the second experiment, sonar data and grab sample cores were taken at nine selected sites in the same proximity of the May survey. The cores were analyzed for sound velocity, density, and porosity and used to calibrate our depositional environment equations.

The geographic area in which these experiments were conducted is the West passage of Narragansett Bay, RI. Narragansett Bay, like many estuaries in the northeast is a glacially deepened river valley that was excavated during the last glaciation (approx. 18000 years before present). As the glacier retreated, glacial till was deposited over bedrock, a glacial lake formed behind a dam of glacial debris and approximately $30 \mathrm{~m}$ of varved, lake sediments were deposited over a period of several thousand years (a typical profile is shown in Fig. 2). With the breaching of the glacial dam and the rise of sea level, several erosional unconformities formed on the surface of the lake sediments followed by the deposition of approximately $10 \mathrm{~m}$ of fine-grained marine estuarine sediments (Fig. 2; Peck and McMaster ${ }^{17}$ ).

The surficial sediments of Narragansett Bay have been studied by McMaster; ${ }^{18}$ the distribution of sediment types in the West Passage is shown in Fig. 6. In this region, McMaster identified five surficial sediment types based on the relative percentages of material defined as gravel $(>2 \mathrm{~mm}$ ); sand $(2-0.062 \mathrm{~mm})$; silt $(0.062-0.005 \mathrm{~mm})$; and clay $(<0.005 \mathrm{~mm})$. The distribution of these sediments is a function of the interactions among: river supply, erosion of preexisting deposits, redistribution by tidal and nontidal circulation patterns, and anthropomorphic effects (dredging).

During the May 1990 survey, a south-north line between Dutch Island and the Wickford breakwater wall and a west-east line between the Wickford breakwater and Hope Island were run with the chirp sonar (Fig. 6). Loran C navigation, with three calibration points along the ship's track, provided accurate $( \pm 10 \mathrm{~m}$ in the absence of abrupt atmospheric changes) positional information. Figure 2 shows a sample chirp sonar profile taken near the Wickford Harbor entrance. This profile, fairly typical of those from Narragansett Bay, shows the succession of geologic features described above.

The large areas of sand north of the Jamestown Bridge, the sandy-silt area west of Wickford Harbor, and clayey silt around Hope Island provided excellent data for calibration of the chirp sonar. In each of these areas, 360 reflection val-

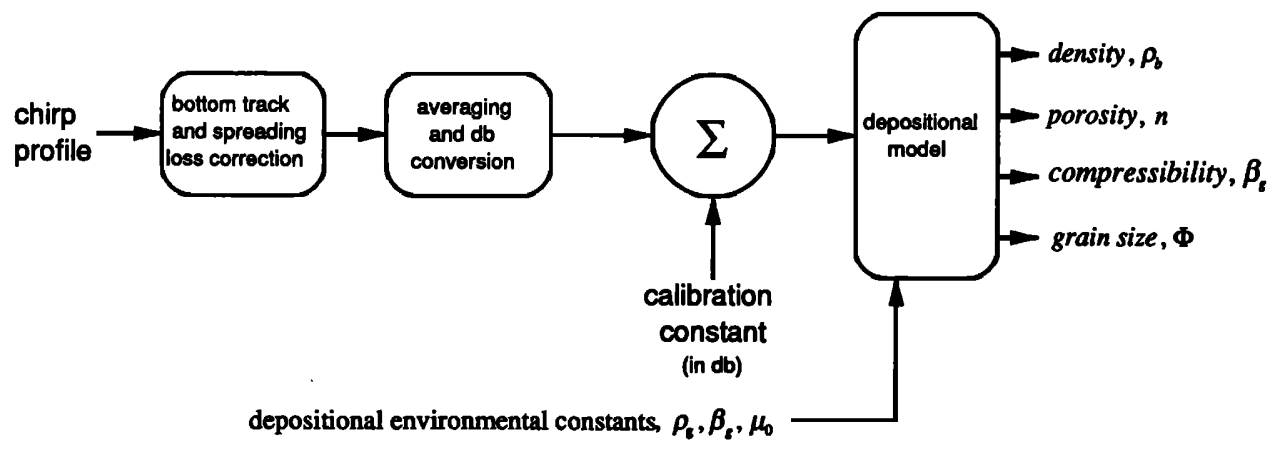

FIG. 5. Model for classification of marine sediments using the chirp sonar. 


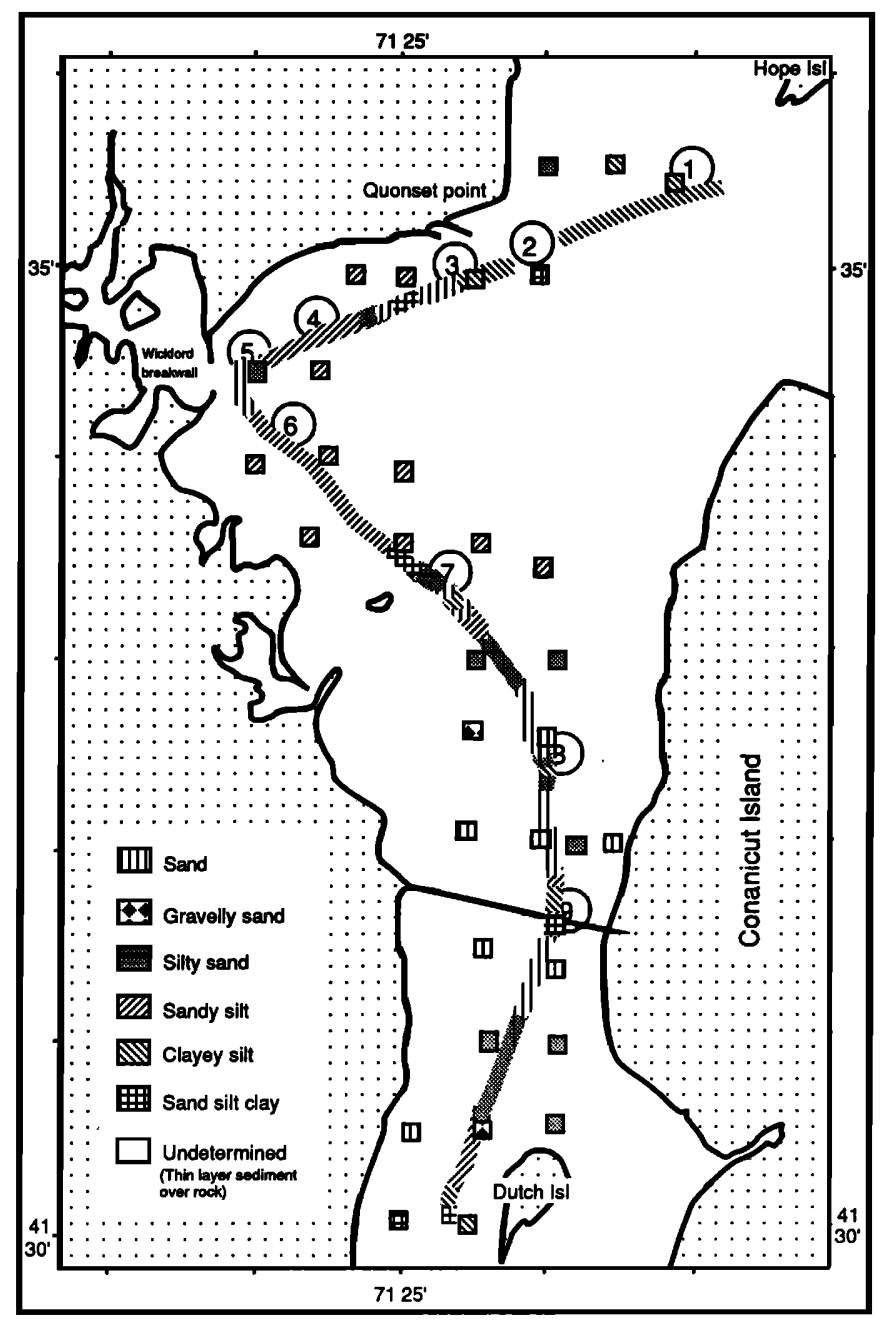

FIG. 6. Comparison of chirp sonar predicted sediment characteristics along the ship's track with core sites taken from McMaster (Ref. 18). Circles mark Sept. 1990 core sites.

ues were acquired and averaged. This corresponds to about $500 \mathrm{~m}$ of the ship's track in each area. The average and standard deviation of the sonar's output (corrected for spherical spreading) are given in Table II for each of the three calibration sites.

The average of the differences between Hamilton's reflection loss values and the output of the chirp sonar at the three calibration sites is $R_{0}=0.8 \mathrm{~dB}$. This reflectivity correction is used to adjust the chirp sonar output allowing prediction of other sediment types using the average reflection

TABLE II. Calibration of the chirp sonar using known bottom types.

\begin{tabular}{lcccc}
\hline \hline $\begin{array}{c}\text { Sediment } \\
\text { type } \\
\left(\text { McMaster }^{18}\right)\end{array}$ & $\begin{array}{c}\text { Mean } \\
\text { chirp } \\
\text { output }^{\mathrm{a}}\end{array}$ & $\begin{array}{c}\text { Standard } \\
\text { deviation }\end{array}$ & $\begin{array}{c}\text { Reflection } \\
\text { loss } \\
\left(\text { Hamilton }^{6}\right)\end{array}$ & $\begin{array}{c}\text { Calibration } \\
\text { constant }\end{array}$ \\
\hline Sand & $-8.9 \mathrm{~dB}$ & $0.5 \mathrm{~dB}$ & $8.0 \mathrm{~dB}$ & $0.9 \mathrm{~dB}$ \\
Sandy silt & $-14.5 \mathrm{~dB}$ & $0.6 \mathrm{~dB}$ & $13.4 \mathrm{~dB}$ & $1.1 \mathrm{~dB}$ \\
Clayey silt & $-15.4 \mathrm{~dB}$ & $0.5 \mathrm{~dB}$ & $15 \mathrm{~dB}$ & $0.4 \mathrm{~dB}$ \\
\hline \hline
\end{tabular}

${ }^{\mathrm{a}}$ Referenced to an arbitrary system constant of $197 \mathrm{~dB}$. coefficients listed in Table I. Note that the reflectivity of silt was not given in Table I, so silt will not be a predicted sediment type in this study.

Using the system calibration constant derived from Table II, the sediment types were estimated from reflectivity measurements made along the ship's track shown in Fig. 6.

In the second experiment in September 1990, core data collected along the same ship track were used to calibrate the impedance-porosity equation (8) for the depositional environment of Narragansett Bay. Table III contains the raw data from the nine stations, marked by circles in Fig. 6. The compressional wave velocity was determined by measuring the phase speed of ultrasonic pulses traveling between transducers inserted into a split sediment core. Acoustic impedance was calculated using the bulk density and velocity measurements.

Also, in the second experiment, in September, 20 acoustic profiles were digitally recorded at each site during the coring operation. Unfortunately, two of these data files (site 2 and site 3 ) were lost. Site 7 was used to calibrate the source level of the chirp sonar. The reflection data were processed to predict the impedance of the sediment at each of the remaining sites. In Table III, the predicted value of impedance, and porosity [using Eq. (8) ] are provided. This comparison of grab sample measurements and chirp sonar estimates of sediment properties show good correlation with the exception of site 9. Analysis of the core at site 9 revealed a thin layer $(5-7 \mathrm{~cm})$ of silt and shells over medium sand which accounts for the higher predicted value of impedance at this site.

All measurements are referenced to $1 \mathrm{~atm}$ and $23^{\circ} \mathrm{C}$. While bottom water temperatures vary seasonally in Narragansett Bay, at any given time they vary only by about 2$3^{\circ} \mathrm{C}$. Bottom temperature measurements made within a few weeks of our survey revealed temperatures ranging from 19 $22{ }^{\circ} \mathrm{C}$. The water depth at the core sites ranged between approximately 4 to $16 \mathrm{~m}$. The maximum possible difference in velocity between actual in situ values and the data we have referenced to $1 \mathrm{~atm}$ and $23^{\circ} \mathrm{C}$ is thus approximately $9 \mathrm{~m} / \mathrm{s}$. Given the small magnitude of this error we have chosen to report values at $1 \mathrm{~atm}$ and $23{ }^{\circ} \mathrm{C}$ in order to keep them comparable with those found in other databases.

While the coring process will inevitably cause some disturbances to the samples, every attempt was made to reduce these effects. The samples were collected with a SmithMacIntyre corer that collects an approximately $20 \times 20 \times 15-\mathrm{cm}$ grab sample. Immediately upon retrieval these cores were subsampled in the middle of the grab (well away from wall disturbances) with polybuterate liner. The subsampled sections were sealed in this manner until they were opened for processing. While very little data exist comparing in situ measurements to core samples measured in the laboratory, a recent study compared laboratory velocity measurements made on core samples with in situ velocity measurements made with a ROV-mounted velocimeter. ${ }^{19}$ The results of this study have shown that the laboratory and in situ measurements can agree within $5 \%$, and more importantly both showed the same relative changes.

The experimental data given in Table III were used in 
TABLE III. Analysis of grab samples taken from Narragansett Bay, RI.

\begin{tabular}{|c|c|c|c|c|c|c|c|}
\hline \multirow{2}{*}{$\begin{array}{c}\begin{array}{c}\text { Station \# } \\
\text { (sediment) }\end{array} \\
1 \text { Silt }\end{array}$} & \multirow{2}{*}{$\begin{array}{c}\begin{array}{c}\text { Density } \\
\text { (bulk) } \\
\left(\mathrm{kg} / \mathrm{m}^{3}\right)\end{array} \\
1630\end{array}$} & \multirow{2}{*}{$\begin{array}{c}\text { Density } \\
\text { (grain) } \\
\left(\mathrm{kg} / \mathrm{m}^{3}\right)\end{array}$} & (core) & $\begin{array}{l}\text { (chirp) } \\
\text { [Eq. (8)] }\end{array}$ & $\begin{array}{c}\text { Velocity } \\
(\mathrm{m} / \mathrm{s})\end{array}$ & (core) & (chirp) \\
\hline & & & 0.67 & 0.66 & 1466 & 2.39 & 2.39 \\
\hline 2 Silt & 1420 & 2670 & 0.76 & N/A & 1458 & 2.07 & $\mathbf{N} / \mathbf{A}^{\mathrm{a}}$ \\
\hline 3 Sand & 2040 & 2680 & 0.40 & N/A & 1720 & 3.51 & $\mathrm{~N} / \mathrm{A}^{\mathrm{a}}$ \\
\hline 4 Silt & 1540 & 2640 & 0.69 & 0.68 & 1472 & 2.27 & 2.32 \\
\hline 5 Sand & 2030 & 2690 & 0.41 & 0.39 & 1645 & 3.34 & 3.48 \\
\hline 6 Sandy silt & 1660 & 2680 & 0.63 & 0.58 & 1494 & 2.48 & 2.64 \\
\hline 7 Sand & 2080 & 2710 & 0.39 & 0.38 & 1703 & 3.54 & $3.54^{\mathrm{b}}$ \\
\hline 8 Sand & 2000 & 2660 & 0.42 & 0.39 & 1679 & 3.36 & 3.48 \\
\hline 9 Silt & 1540 & 2640 & 0.69 & 0.45 & 1424 & 2.19 & 3.17 \\
\hline
\end{tabular}

a Data lost at this site.

${ }^{b}$ Calibration site.

the least-squares procedure to obtain the depositional constants $\left(\rho_{g}, \beta_{g}, \mu_{0}\right)$. The results of the numerical analysis are shown in Fig. 7. For comparison, core data from the equatorial Pacific and Emerald Basin, off Nova Scotia are included. The equatorial Pacific samples are composed of calcareous and siliceous microfossils; the relative proportions of these components are a function of dissolution and thus the chemical state of bottom waters which, in turn responds to changes in global climate. ${ }^{20}$ The fundamental difference between the biogeneous particles of the equatorial Pacific and the terrigenously derived particles of Narragansett Bay is apparent by noting the larger shear coefficient and higher compressibility of the equatorial Pacific sediments. The large shear coefficient is consistent with the spiny nature of many biogeneous particles (and thus pronounced grain-tograin interlocking); the high compressibility is most likely the result of the open, hollow structure of the biogeneous particles resulting in more enclosed water as compared to the predominantly incompressible quartz particles of Narragansett Bay. At the relatively high frequency of the core velocity measurement $(200-1000 \mathrm{kHz})$ these partially open chambers appear closed and thus each particle acts more compressible than an equivalent solid grain.

The Emerald Basin data are from long $(18 \mathrm{~m})$ piston

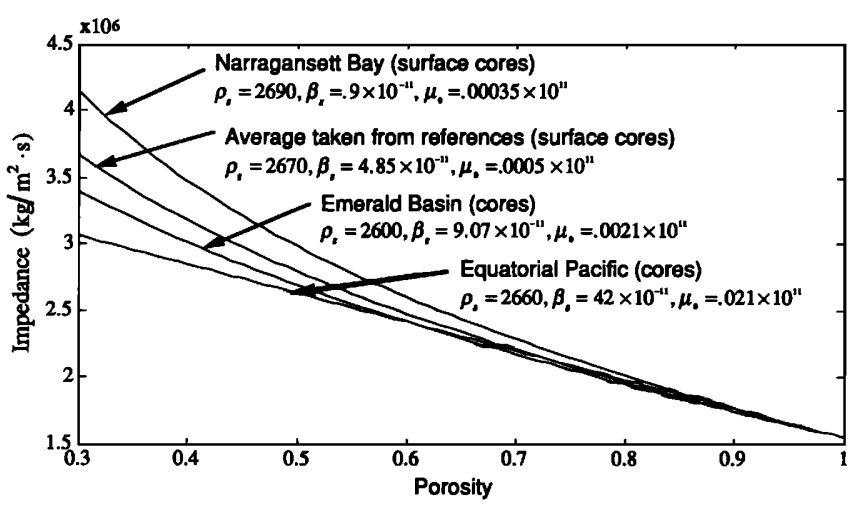

FIG. 7. Impedance dependence on porosity for various depositional environments (units: $\rho_{g}-\mathrm{kg} / \mathrm{m}^{3}, \beta_{g}-\mathrm{m}^{2} / \mathrm{N}, \mu_{0}-\mathrm{N} / \mathrm{m}^{2}$ ). cores in a deep $(300 \mathrm{~m})$ proglacial basin about $80 \mathrm{~km}$ off Halifax. $^{21}$ While this environment has also been influenced by glacial processes, its relatively deeper setting (as compared to Narragansett Bay) results in a much higher percentage of clay-rich sediments. These clays form card-house structures and thus demonstrate higher compressibility than the relatively coarse material of Narragansett Bay. In addition, the inclusion of subsurface samples in the Emerald Basin data set will unquestionably show the effects of compaction on the rigidity of the sediment sample.

Finally, the Narragansett Bay cores show higher impedance at low porosity than the average curve taken for surficial sediments from the literature (Fig. 7). This is most likely due to the extremely high sand percentages $(80 \%-90 \%)$ found in the low porosity samples from Narragansett Bay. Such high sand percentages greatly increase velocity (and thus impedance) and are uncommon in the samples reported in the literature.

\section{CONCLUSIONS}

The proposed model for acoustic sediment classification is dependent on the depositional environment. The parameters that characterize a depositional environment are grain density $\rho_{g}$, grain compressibility $\beta_{g}$, and the rigidity constant $\mu_{0}$. The measured reflectivity of the seabed is used to calculate the acoustic impedance of surficial sediments. If the depositional environment and its parameters are known, relationships presented in this paper allow prediction of sound speed, rigidity, porosity, and bulk density from acoustic impedance. Once a database of parameters is obtained for each depositional environment in the ocean, physical sediment properties can be directly estimated from seafloor reflection measurements made by a quantitative reflection profiler.

\section{ACKNOWLEDGMENT}

This research was supported by the Office of Naval Research (Geo-Acoustics/Arctic Science Division; program manager, Dr. J Kravitz) under contract \# N00014-91-J1082. 
${ }^{1}$ S. G. Schock, and L. R. LeBlanc, and L. A. Mayer, "Chirp subbottom profiler for quantitative sediment analysis," Geophysics 54, 445-450 (1989).

${ }^{2}$ S. G. Schock and L. R. LeBlanc, “Chirp sonar: new technology for subbottom profiling," Sea Technol. 31, 35-43 (1990).

${ }^{3}$ R. T. Bachman, "Acoustic and physical property relationships in marine sediments," J. Acoust. Soc. Am. 78, 616-621 (1985).

${ }^{4}$ S. Buchan, F. C. D. Dewes, A. S. G. Jones, D. M. McCann, and D. Taylor Smith, "The acoustic and geotechnical properties of North Atlantic Cores," University College of North Wales, Marine Science Laboratories, 1 and 2 (1971).

${ }^{5}$ E. L. Hamilton, H. P. Bucker, D. L. Keir, and J. A. Whitney, "Velocities of compressional and shear waves in marine sediments determined in situ from a research submersible," J. Geophys. Res. 75, 4039-4049 (1970).

${ }^{6}$ E. L. Hamilton, "Reflection coefficients and bottom losses at normal incidence computed from pacific sediment properties," Geophysics 35, 9951004 (1970).

${ }^{7}$ E. L. Hamilton, G. Shumway, H. W. Menard, and C. J. Shipek, “Acoustic and other physical properties of shallow-water sediments off San Diego," J. Acoust. Soc. Am. 28, 1-15 (1956).

${ }^{8}$ R. W. Faas, "Analysis of the relationship between acoustic reflectivity and sediment porosity," Geophysics 34, 546-553 (1969).

${ }^{9}$ M. A. Biot, "Theory of propagation of elastic waves in a fluid-saturated porous solid. I. Low-frequency range," J. Acoust. Soc. Am. 28, 168-178 (1956).

${ }^{10} \mathrm{M}$. A. Biot, "Theory of propagation of elastic waves in a fluid-saturated porous solid. II. Higher frequency range," J. Acoust. Soc. Am. 28, 179191 (1956).
${ }^{11}$ R. D. Stoll, "Acoustic waves in ocean sediments," Geophysics 42, 751725 (1977).

${ }^{12}$ L. R. LeBlanc, S. G. Schock, and S. Panda, "Pulse and aperture design considerations for a marine sediment classification chirp sonar," Proceedings of The Marine Technology Society Conference, Nov. 91, Vol. II, 820 ( 1991 ).

${ }^{13}$ M. A. Biot, "Generalized theory of acoustic propagation in porous dissipative media," J. Acoust. Soc. Am. 34, 1254-1264 (1962).

${ }^{14}$ R. J. Urick, Principles of Underwater Sound for Engineers (McGrawHill, New York, 1967)

${ }^{15}$ W. M. Ewing, W. S. Jardetsky, and F. Press, Elastic Waves in Layered Media (McGraw-Hill, New York, 1957).

${ }^{16}$ F. P. Shepard, "Nomenclature based on sand-silt-clay ratios," J. Sed. Petrol. 24, 151-158 (1954).

${ }^{17}$ J. Peck, and R. L. McMaster, "The geology beneath the Jamestown Bridge," Maritimes 34(3), 4-6 (1990).

${ }^{18}$ R. L. McMaster, "Sediments of Narragansett Bay system and Rhode Island Sound," J. Sed. Petrol. 30, 249-274 (1960).

${ }^{19}$ L. A. Mayer, P. Bugden, and P. Simpkin, "The measurement of in situ velocity and attenuation in marine sediments," DREP Rep. \#W7707-70014/01-OSC, 58 pp. (1989).

${ }^{20}$ L. A. Mayer, "Deep-sea carbonates: acoustic, physical \& stratigraphic properties," J. Sed. Petrol. 49, 819-836 (1979).

${ }^{21}$ K. Moran, D. J. W. Piper, L. A. Mayer, R. Courtney, A. Driscoll, and F. Hall, "Scientific results of long coring on the eastern Canadian continental margin," Proceedings of the Offshore Technology Conference, Houston, Texas, Paper No. 5963, 65-71 (1989). 